\title{
Factors Affecting the Utilization of Family Planning among Women Attending Selected Health Centers in Ile Ife, Osun State, Nigeria
}

\author{
Article by Agunbiade Funmilayo B \\ RN, RM, CERT. in Family Planning, CRNA, BSN \\ Assistant Director of Nursing Services, Department of Anaesthesia, Obafemi Awolowo \\ University Teaching Hospitals Complex, Ile-Ife, Nigeria \\ E-mail: abolanle@texilaconnect.com
}

\begin{abstract}
Many unintended pregnancies and illegal abortions contributes significantly to the high mortality rate in Nigeria, which signifies the unmet needs for family planning among women of reproductive age, which could be affected by myriads of factors. Hence, this study assesses factors influencing the utilization of family planning methods among women attending selected health centers in Ile Ife. Osun State. Nigeria.

Findings showed that more than two-third (68.6\%) had ever used a family planning method. Meanwhile, about two-third (60.4\%) were currently using a family planning method, while $39.6 \%$ were not using any method. Majority (26.3\%) rated condom as the most effective method of contraception. Factors identified as militating against the utilization of contraceptive use were; fear of side effects (80.2\%), personal dislike (71.7\%), opposition of spouse (63.5\%) and unwelcoming attitude of health workers (61.1\%) and non-effectiveness of family planning services (54.3\%). Hypothesis testing revealed a strong relationship between fear of side effects and utilization of family planning services $\left(X^{2}=\right.$ 26.091, $d f=1$ and $p=0.001$ at 0.05 significant value). However, there is no significant relationship between spouse opposition and utilization of family planning services $\left(X^{2}=1.171, d f=1, p=0.279\right.$ at 0.05 significant value).

In conclusion, although a good number of the respondents were using a family planning method, some of them were not still using it. Hence, the need for health care provider to educate based on isolated factors such as side effects, preference, spousal opposition that influence contraceptive use among women of child bearing age.
\end{abstract}

Keywords: Factors influencing contraceptive use among Lori Ashford, Donna Clifton, and Toshiko Kaneda, The World's Youth 2006.

\section{Introduction}

It has been estimated that two-thirds of all unintended pregnancies in developing countries occur among women and adolescents who do not use contraceptives (Mbizvo \& Zaidi, 2010). In 2014, it was reported that two hundred and twenty-five million women in developing regions had an unmet need for modern contraception (Singh, Darroch and Ashford, 2014). (Of this total, 160 million were using no method and 65 million were using a traditional method.) The total changed little over the past decade, mainly because increases in contraceptive use have barely kept up with growing populations and rising desire for smaller families. The health implications of such a large unmet need are profound. Every year, an estimated 74 million unintended pregnancies occur in developing regions, the great majority of which are among women using no contraception or a traditional method. Should the need for modern contraception be met among those who were supposed to be using it but not using it, fifty-two millions of these pregnancies not planned could be averted, thereby preventing the deaths of 70,000 women from pregnancy-related causes (Singh, et al, 2014). In Nigeria, the contraceptive prevalence rate has remained low (Olugbenga-Bello, Abodurin and Adeomi, 2011). Meanwhile, literature shows that reduced contraceptive usage is associated with high maternal mortality indices, and Nigeria records one of the highest ratio, with maternal mortality ratio of 545 deaths per 100,000 live births (Nigeria Demographic and Health Survey, 2008). Igbodekwe, Oladimeji, Oladimeji, Adeoye, Akpa \& Lawson (2014) in a review of use of contraceptives using a nationally representative data in the 2008 National 
Demographic and Health Survey, found that the overall rate for current contraceptive use was $13.2 \%$, while the rate for modern methods was $9.4 \%$.

Family planning could nip to the bud up to one-third maternal deaths by allowing women to delay motherhood, space births, avoid unintended pregnancies and abortions, and stop child bearing when they have reached their desired family size (Lori, Donna and Toshiko (2006). Contraception is the use of various devices, drugs, agents, sexual practices or surgical procedures to prevent pregnancy (WHO, 2011). They are usually referred to as birth control methods (WHO, 2011). By helping women prevent unintended pregnancies, programs can reduce unwanted births and unsafe abortions, and improve maternal and child health (Singh, Darroch and Ashford, 2014). These gains can also contribute to other development objectives, such as curbing poverty and slowing population growth (Canning and Schultz, 2012). Enabling women to act on their pregnancy preferences has become a high priority on the global development agenda. Not long past strategies have called for improving the unmet need for modern contraception, which arises when women want to avoid a pregnancy but are using no method or a traditional one. The most prominent of these initiatives is Family Planning 2020, a global partnership launched in 2012 that aims to add 120 million new users of modern contraceptives in the world's 69 poorest countries by 2020 (Family Planning Summit, 2012).

Several factors play an important role in the use of contraceptives among women of childbearing age. The identification of these factors is crucial to the planning and implementation of suitable family planning programmers (Kabir, Saha, Oliveras and Gazi, 2013). Many studies in Sub-Sahara Africa show that there are many factors that inhibit the use of modern contraceptives among adolescents. These barriers include poor knowledge of contraceptive, fears and rumours about side effect, and unsupportive or negative influences of partners and family members (Williamson, Parkes, Wight, Petticrew and Hart, 2009). Family members put pressure on adolescents, especially female adolescents to give birth because they are not sure whether she would be fertile after using contraceptives. Others also reject contraceptives for religious reasons (Williamson et al, 2009). The use of contraceptives by teenagers has also been found to be a factors of socio-economic status, knowledge about contraceptives, attitudes about issues related to contraceptives, residential area, educational status, counseling received about contraceptives, attitudes of the contraceptive providers, and cultural values, beliefs and norms (Kanku and Mash, 2010).

In 2012, more than one-third of women in the United States who were not using a contraceptive method when they had an unintended pregnancy said it was because they did not think they could get pregnant (Mosher, Jones and Abma, 2012). It was the most common reason the women gave for not using contraception, and there was no significant variation in the proportions of women who cited this reason by age, marital status or income. Concern about side effects and health risks appears somewhat less common among sexually active never married women than among married women. Concern about side effects is also high among married women in Ghana, and studies there have shown that many educated, urban women avoid hormonal methods (Machiyama and Cleland, 2014). A promising study in Kenya showed that improvements in the quality of care were positively associated with modern contraceptive use, particularly among young and less educated women (Tumlinson, Okigbo and Speizer, 2015).

Studies in the Philippines among adolescents also show poverty, lack of knowledge on contraceptives and having infrequent sex as reasons for contraceptive non-use (Gipson, Hirz and Avila, 2011). Religion has also been a barrier to contraceptive use for decades where children are regarded as gifts or blessings from God (Gipson et al., 2011). This is found mostly among the Catholics and Muslims who see contraceptive use as a license for illicit or extra marital sexual behavior or indiscriminate sexual behavior (Gipson et al., 2011). Studies in Africa have inquired into the healthcare providers' attitude towards providing contraceptives for unmarried adolescents and reports reveal that many providers have negative attitudes. For instance, a Ugandan study reported that most of the providers had negative attitudes towards the provision of contraceptives for young people and were not prepared or were hesitant to give young people contraceptives (Ahanonu, 2013). As such, they imposed non-evidence based age restrictions and consent requirements (Ahanonu, 2013). A major reason reported to be responsible for the resistance of service providers to provide contraceptive services to 
adolescents is the belief that it promotes sexual promiscuity and that by restricting access to services, they were protecting both the client and the society (Ahanonu, 2013).

\section{Objectives}

The main objectives of this study were to;

1. To assess the level of utilization of family planning methods among women attending selected health centres in Ile- Ife, Osun State, Nigeria.

2 To identify factors affecting the use of family planning methods among respondents.

\section{Methodology}

The design was descriptive analytical survey as it helped the researcher to describe and analyze respondents' view statistically. This research was carried out among women of child bearing age attending three various selected health centers in Ile-Ife; Aderemi Health Centre, Enuwa Health Centre, and Eleyele Comprehensive Health Centre, Ile-Ife. Multistage sampling was used to select 293 participants; at the first level, 3 health centers were purposively selected. At the second level, proportionate sampling was done based on clinic attendance of each health center, and lastly, incidental sampling method was used to select 293 respondents from all the clinics; Eleyele (107), Enuwa (96) and Aderemi (90), which formed the sample size.

The data was collected using a self-structured questionnaire which contained questions drawn in open ended and close ended forms. The questionnaire has three sections with section $\mathbf{A}$ exploring the socio-demographic characteristics of the samples, section B exploring the attitude and perception of women about family planning and section $\mathbf{C}$ exploring the factors affecting women's choice in utilizing family planning services.

The data collection was a face-to-face distribution of questionnaires to the respondents by hand. The questionnaires were also translated into Yoruba language putting into consideration some respondents who could not read or write in English. Informed consent was gained from all the respondents as they were briefed on the research topics and given opportunity to decide if to participate in the study or not, and all the information on the questionnaires issued were treated with strict confidentiality. The data collected was analyzed using a descriptive (frequency tables) and inferential statistics (correlations), graphs and Statistical Package for Social Sciences (SPSS) as statistical tools.

\section{Results}

Demographic Profile of the of Respondents $(n=293)$

\begin{tabular}{|l|l|l|l|}
\hline Demographic Variables & Frequency & Percent \\
\hline \multirow{4}{*}{ Age of the respondents } & $15-24$ & 75 & 25.6 \\
\cline { 2 - 4 } & $25-34$ & 158 & 53.9 \\
\cline { 2 - 4 } & $35-44$ & 40 & 13.7 \\
\cline { 2 - 4 } & $45-54$ & 20 & 6.8 \\
\hline \multirow{2}{*}{$\begin{array}{l}\text { Religion of the } \\
\text { respondents }\end{array}$} & Christianity & 215 & 73.4 \\
\hline \multirow{4}{*}{ Marital status } & Islam & 78 & 26.6 \\
\hline \multirow{4}{*}{ Residence } & Single & 60 & 20.5 \\
\cline { 2 - 4 } & Married & 224 & 76.5 \\
\cline { 2 - 4 } & Divorced & 9 & 3.1 \\
\hline Educational level & Urban & 234 & 79.5 \\
\cline { 2 - 4 } & Rural & 60 & 20.5 \\
\hline \multirow{2}{*}{$\begin{array}{l}\text { Partners Educational } \\
\text { Level }\end{array}$} & Secondary & 56 & 19.1 \\
\cline { 2 - 4 } & Tertiary & 237 & 80.9 \\
\cline { 2 - 4 } & Secondary & 39 & 13.3 \\
\cline { 2 - 4 } & Tertiary & 227 & 77.5 \\
\hline Occupation & No Partner & 27 & 9.2 \\
\hline
\end{tabular}


DOI: $10.21522 /$ TIJNR.2015.03.02.Art012

ISSN: $2520-3126$

\begin{tabular}{|l|l|l|l|}
\hline \multirow{5}{*}{ Family Setting } & Student & 108 & 36.9 \\
\cline { 2 - 4 } & Self Employed & 79 & 27 \\
\cline { 2 - 4 } & Civil Service & 87 & 29.7 \\
\hline Ideal Number of Children & Monogamous & 238 & 81.2 \\
\cline { 2 - 4 } & Polygamous & 55 & 18.8 \\
\cline { 2 - 4 } Children & Two & 89 & 30.4 \\
\cline { 2 - 4 } & Three & 75 & 25.6 \\
\cline { 2 - 4 } & Four & 129 & 44 \\
\hline \multirow{5}{*}{\begin{tabular}{l} 
Number of living \\
\cline { 2 - 4 }
\end{tabular}} & One child at all & 29 & 9.9 \\
\cline { 2 - 4 } & Two & 28 & 9.6 \\
\cline { 2 - 4 } & Three & 111 & 37.9 \\
\cline { 2 - 4 } & Four & 30 & 29.4 \\
\cline { 2 - 4 } & Five and above & 9 & 10.2 \\
\hline & No child & 29 & 3.1 \\
\cline { 2 - 4 } & $\begin{array}{l}\text { Same number of } \\
\text { male and Female }\end{array}$ & 72 & 24.6 \\
\cline { 2 - 4 } & Female > Male & 48 & 16.4 \\
\cline { 2 - 4 } & Male > Female & 47 & 16 \\
\cline { 2 - 4 } & No Female & 49 & 16.7 \\
\cline { 2 - 4 } & No Male & 48 & 16.4 \\
\hline
\end{tabular}

Table 1 above showed $53.9 \%$ of the respondents were aged $25-34$, about $73.4 \%$ were Christians, $79.5 \%$ resides in urban setting, $20.5 \%$ were single, while 76.5 were married, majority $(80.9 \%)$ of them and their spouses $(77.5 \%)$ attended tertiary institution, larger percentage $(56.7 \%)$ were employed and $36.9 \%$ were students. The table also revealed that majority of the respondents was from monogamous setting; the ideal number of children by majority of the respondents was four.

Table 2. Contraceptive use among respondents

\begin{tabular}{|l|l|l|l|}
\hline Variables & Yes (\%) & No (\%) & Total (\%) \\
\hline Ever use contraceptive before & $201(68.6 \%)$ & $92(31.4 \%)$ & $293(100 \%)$ \\
\hline $\begin{array}{l}\text { Do you use any family } \\
\text { planning presently? }\end{array}$ & $177(60.4 \%)$ & $116(39.6 \%)$ & $293(100 \%)$ \\
\hline
\end{tabular}

In table 2, more than two-third (68.6\%) of the respondents have used contraceptive before. Majority $(60.4 \%)$ were using contraceptive presently, while $39.6 \%$ were not using it.

Table 3. Distribution of respondents based on their rating of the effectiveness of family planning methods

\begin{tabular}{|l|l|l|}
\hline Family Planning Methods & Frequency & Percent \\
\hline Pills & 9 & 3.1 \\
\hline Injectables & 38 & 13.0 \\
\hline Condoms & 77 & 26.3 \\
\hline Sterilization & 9 & 3.1 \\
\hline Periodic abstinence & 12 & 4.1 \\
\hline Withdrawal & 19 & 6.5 \\
\hline More than one methods & 11 & 3.8 \\
\hline Not using any method & 116 & 39.6 \\
\hline No response & 2 & $0.7 \%$ \\
\hline Total & 293 & 100.0 \\
\hline
\end{tabular}


The table above showed that more than a quarter of the respondents $(26.3 \%)$ rated condom as the most effective, followed by injectables, which was $13 \%$. However, $39.6 \%$ of the respondents could not rate the effectiveness of the contraceptive methods as they were not using any method at all.

Table 4: Distribution of respondents based on factors reducing their choices and utilization of family planning services

\begin{tabular}{|l|l|l|}
\hline Variables & Yes & No \\
\hline Fear of side effects (bleeding, headaches etc.) & $235(80.2 \%)$ & $58(19.8 \%)$ \\
\hline Personal Dislike & $210(71.7 \%)$ & $83(28.3 \%)$ \\
\hline Opposition of Spouse & $186(63.5 \%)$ & $107(36.5 \%)$ \\
\hline $\begin{array}{l}\text { Unwelcoming attitude of Health Care } \\
\text { Providers }\end{array}$ & $179(61.1 \%)$ & $\begin{array}{l}114 \\
(38.9 \%)\end{array}$ \\
\hline Non- effectiveness of Family Planning & $159(54.3 \%)$ & $134(45.7 \%)$ \\
\hline Reduces Coital Satisfaction & $146(49.8 \%)$ & $147(50.2 \%)$ \\
\hline Not having/ Infrequent Sex & $130(44.4 \%)$ & $163(55.6 \%)$ \\
\hline $\begin{array}{l}\text { Lack of Knowledge of family planning } \\
\text { services }\end{array}$ & $124(42.3 \%)$ & $169(57.7 \%)$ \\
\hline Non-availability of Family Planning Methods & $115(39.2 \%)$ & $178(60.8 \%)$ \\
\hline Religious Prohibition & $109(37.2 \%)$ & $184(62.8 \%)$ \\
\hline Distance to Service Provider & $103(35.2 \%)$ & $\begin{array}{l}190 \\
(64.8 \%)\end{array}$ \\
\hline Need for Female Children & $68(23.2 \%)$ & $225(76.8 \%)$ \\
\hline Cost too much & $58(19.8 \%)$ & $\begin{array}{l}235 \\
(80.2 \%)\end{array}$ \\
\hline Need for Male Children & $57(19.5 \%)$ & $\begin{array}{l}236 \\
(80.5 \%)\end{array}$ \\
\hline
\end{tabular}

Ranked most of the factors reducing the utilization of family planning services were: fear of side effects $(80.2 \%)$, personal dislike $(71.7 \%)$, and opposition of spouse $(63.5 \%)$, negative attitude of health workers $(61.1 \%)$ and non-effectiveness of family planning services $(54.3 \%)$.

Table 5. Association between fear of side effects and utilization of family planning services

\begin{tabular}{|c|c|c|c|c|c|c|c|}
\hline & & \multicolumn{3}{|c|}{$\begin{array}{l}\text { Fear of side effects } \\
\text { (bleeding, headaches, } \\
\text { cessation of menses) }\end{array}$} & \multirow[t]{2}{*}{$\mathrm{X}^{2}$} & \multirow[t]{2}{*}{ D } & \multirow[t]{2}{*}{$\mathbf{P}$} \\
\hline & & No & Yes & Total & & & \\
\hline \multirow{3}{*}{$\begin{array}{l}\text { Do you use any family } \\
\text { planning presently? }\end{array}$} & No & 40 & 76 & 116 & \multirow[t]{3}{*}{26.091} & \multirow[t]{3}{*}{1} & \multirow[t]{3}{*}{.001} \\
\hline & Yes & 18 & 159 & 177 & & & \\
\hline & Total & 58 & 235 & 293 & & & \\
\hline
\end{tabular}

Using Pearson chi square, $\mathrm{X}^{2}=26.09, \mathrm{P}=0.001$, which is less than 0.05 Sig. value. There is a significant relationship between fear of side effects of family planning methods and utilization of family planning services. 
DOI: $10.21522 /$ TIJNR.2015.03.02.Art012

ISSN: $2520-3126$

Table 6. Association between spouse opposition and utilization of family planning services

\begin{tabular}{|c|c|c|c|c|c|c|c|}
\hline & & \multicolumn{3}{|c|}{ Opposition of the spouse } & \multirow[t]{2}{*}{$\mathbf{X}^{2}$} & \multirow[t]{2}{*}{ Df } & \multirow[t]{2}{*}{$\mathbf{P}$} \\
\hline & & No & Yes & Total & & & \\
\hline \multirow{3}{*}{$\begin{array}{l}\text { Do you use any family } \\
\text { planning presently? }\end{array}$} & No & 38 & 78 & 116 & \multirow[t]{2}{*}{1.171} & \multirow[t]{2}{*}{1} & \multirow[t]{2}{*}{0.279} \\
\hline & Yes & 69 & 108 & 177 & & & \\
\hline & Total & 107 & 186 & 293 & & & \\
\hline
\end{tabular}

Using Pearson chi square, $\mathrm{X}^{2}=1.17, \mathrm{P}=0.279$, which is greater than 0.05 Sig. value. There is no significant relationship between spouse opposition to family planning methods and utilization of family planning services" was accepted.

\section{Discussion of findings}

This study assessed the factors influencing the utilization of family planning methods among women attending selected health centers in Ile-Ife. 293 respondents partook in the study. The sociodemographic characteristics showed a little over half (53.9\%) of the respondents were aged 25-34, majority were Christians, married, had tertiary education, and from monogamous setting; the ideal number of children for larger percentage (44\%) of the respondents was four.

This study assessed the level of utilization of contraception among respondents. The result showed that more than two-third of the respondents $(68.6 \%)$ had ever used contraceptive before, while majority (60.4\%) were still using contraception presently. Meanwhile, significant number (39.6\%) was still not using contraception. This is in contrast with Olugbenga-Bello, et al (2011) who reported that contraceptive use remained low. It is also at variance with Igbodekwe, et al, (2014). In a review of use of contraceptives using a nationally representative data in the 2008 National Demographic and Health Survey, the overall rate for current contraceptive use was $13.2 \%$, while the rate for modern methods was $9.4 \%$.

On the factors reducing contraceptive choices among respondents, majority $(80.2 \%)$ agreed that fear of side effect prevented them from utilizing family planning services. This supports Machiyama and Cleland (2014), they submitted that concern about side effects and health risks appear somewhat a strong factor affecting contraceptive use. Also, majority (63.5\%) agreed that spouse opposition reduced their choice of family planning, which supports the view of Olaitan (2009) that "the woman's husband is one of many socially significant actors who might discourage or oppose a woman who wishes to use contraception. Larger percentage $(71.7 \%)$ had personal dislike for family planning. Majority $(61.1 \%)$ also saw unwelcoming attitude of the family planning providers as reducing their choices. This validates the findings of Ahanonu (2013) in Uganda that most of the providers had negative attitudes towards the provision of contraceptives for young people and were not prepared or were hesitant to give young people contraceptives.

The study found the association between fear of side effects and utilization of family planning services using chi square. The result showed a significant relationship between fear of side effects and utilization of family planning services $(\mathrm{P}=0.001)$, this further corroborates the findings of (Machiyama and Cleland, 2014). The study assessed the association of spouse opposition and utilization of family planning using chi square. Therefore, there is no significant relationship between spouse opposition and respondents' utilization of family planning $(\mathrm{P}=0.279)$.

\section{Summary}

The study examined factors affecting the utilization of family planning among women attending selected health centers in Ile-Ife, Osun State, Nigeria. . The findings and recommendations should serve to improve the use of family planning by women of child bearing age, the role of the family planning providers, spouse involvement in family planning and government in making essential provisions for women's health promotion and their families to support the millennium development goal, support safe motherhood and accelerate the country's progress towards reducing poverty. 


\section{Conclusion}

In this study, it was observed while majority were using contraception, significant number of women of child bearing age is ambivalent about using contraception, reasons not far-fetched from fear of side effect and spouse opposition. Therefore, the need to further intensify efforts to create awareness on benefits of family planning and reaching out to the society by the health care providers in achieving the millennium development goals should be redressed.

\section{Implications for nursing practice}

The findings from this study implicate the need for nurses and family planning providers to include information that would educate couples on their family planning choices, reproductive behavior, relationship, and decision-making.

Secondly, family planning provider and nurses need to consider those variables tested when designing intervention programs for modifying couples attitudes towards family planning choices.

Finally, all those in the helping professions should design programs for couples on the social and economic benefit on couple's decision-making on family planning choices.

\section{Recommendations}

Having studied the factors influencing the utilization of family planning among women in selected health centers in Ile-Ife, Osun State, Nigeria, the following recommendations were made:

1. Health care providers especially nurses should educate women based on isolated factors affecting contraceptive use, such as side effects, preference, and spousal opposition.

2. Societies and communities should give a couple of advice to their neighbors on the importance of family planning in order to promote healthy living.

3. Religious leaders should encourage their followers on the needs for family planning choice as related to their holy book. Information from such people aids wider acceptance.

4. Community leaders should discourage the habit of not having family planning choice in their cultural norms because person's cultural and social environment influence decisions on family planning.

5. Federal Government should build Reproductive Health Centers, where family planning education would be given to couples on the choice of family planning for both educated and non-educated couples.

6. Family planning service providers should educate the couples on the effectiveness of family planning choice and benefits as these ensure acceptance and utilization.

7. Every couple should be discouraged about the thought of health risk of family planning choice.

\section{References}

[1].Ahanonu, E. L. (2013). Attitudes of Healthcare Providers towards Providing Contraceptives for Unmarried Adolescents in Ibadan, Nigeria. Journal of Family and Reproductive Health Vol. 8, No. 1,

[2].Canning, D. and Schultz, T.P. (2012). The economic consequences of reproductive health and family planning, Lancet, 380(9837):165-171.

[3].Family Planning Summit - July 2012,

http://www.who.int/workforcealliance/media/events/2012/LondonSummitonFamilyPlanningOverview.pdf.

[4].Gipson, J. D., Hirz, A. E., \& Avila, J. L. (2011). Perceptions and practices of illegal abortion among urban young adults in the Philippines: a qualitative study. Studies in family planning, 42(4), 261-272.

[5].Igbodekwe, F.C., Oladimeji, O., Oladimeji, K.E., Adeoye, I.A., Akpa, O.M., \& Lawson, L. (2014). Utilisation of Modern Contraceptive among Women of Childbearing Age in Resource Constraint Setting: Evidence from 2008 National Demographic and Health Survey in Nigeria. Journal of Health Science, 4(3): 72-78.

[6].Kabir, H., Saha, N. C., Oliveras, E. and Gazi, R. (2013). "Association of programmatic factors with low contraceptive prevalence rates in a rural area of Bangladesh," Reproductive Health, vol. 10(31), 2013.

[7].Kanku, T., \& Mash, R. (2010). Attitudes, perceptions and understanding amongst teenagers regarding teenage pregnancy, sexuality and contraception in Taung. South African Family Practic, 52(6).

[8].Lori Ashford, Donna Clifton, and Toshiko Kaneda, The World's Youth 2006 (Washington, DC: Population Reference Bureau, 2006). 
DOI: $10.21522 /$ TIJNR.2015.03.02.Art012

ISSN: $2520-3126$

[9].Machiyama, K. and Cleland, J. (2014). Unmet need for family planning in Ghana: the shifting contributions of lack of access and attitudinal resistance, Studies in Family Planning, 45(2):203-226.

[10]. Mbizvo, M. T., \& Zaidi, S. (2010). Addressing critical gaps in achieving universal access to sexual and reproductive health (SRH): the case for improving adolescent SRH, preventing unsafe abortion, and enhancing linkages between SRH and HIV interventions. International Journal of Gynecology \& Obstetrics, 110, S3-S6.

[11]. Mosher, W.D., Jones, J., and Abma, J.C., (2012). Intended and unintended birth in the Unites States: 19822010, National Health Statistics Report No. 55, Hyattsville, and MD: National Center for Health Statistics, 2012.

[12]. Nigeria Demographic and Health Survey (2008). National Population Commission and ICF micro, Calverton, MD 0705, USA 2008.

[13]. Olugbenga-Bello, A. I., Abodunrin, O. L., and Adeomi, A. A. (2011). "Contraceptive Practices among Women in Rural Communities in South-Western Nigeria," Global Journal of Medical research Vol. 11(2), 2011.

[14]. Singh, S., Darroch, J.E. and Ashford, L.S., (2014). Adding It Up: The Costs and Benefits of Investing in Sexual and Reproductive Health 2014, New York: Guttmacher Institute.

[15]. Tumlinson, K., Okigbo, C.C., \& Speizer, I.S., (2015). Quality of care and contraceptive use in urban Kenya, International Perspectives on Sexual and Reproductive Health, 2015, 41(2):69-79.

[16]. Williamson, L. M., Parkes, A., Wight, D., Petticrew, M., \& Hart, G. J. (2009). Limits to modern contraceptive use among young women in developing countries: a systematic review of qualitative research. Reprod Health, 6(3), 1-12. 